\title{
PERANCANGAN PEMBANGKIT LISTRIK ALTERNATIF DENGAN MEMANFAATKAN FLYWHEEL SEBAGAI PENYIMPAN ENERGI BERDAYA 1000 WATT
}

\author{
Ruslim $^{1^{*}}$, WiwingHerianto ${ }^{2}$, Hadi Santoso ${ }^{3}$ \\ 1,2,3 Jurusan Teknik Mesin, Universitas Borneo Tarakan \\ Jl. Amal Lama No. 1, Kel. Pantai Amal, Kec. Tarakan Timur, Kota Tarakan Kalimantan Utara \\ *E-mail: ruslim@Borneo.ac.id
}

\begin{abstract}
ABSTRAC: The increase in the need for electrical energy is influenced by the increase in population. This increase is not matched by the availability of electrical energy, especially in some remote areas in North Kalimantan. Free energy-based power plants are an alternative solution to meet the availability of electrical energy. Free energy is a method of utilizing energy without using fuel. One of the free energy developed is flywheel generator. The purpose of this study is to design a power generation system using the flywheel as energy storage and to calculate and analyze flywheel power. The results of this study indicate that a power plant design has been carried out using a flywheel as an energy store with a flywheel power of 1,185 watts, where with the use of a flywheel in a power plant that uses a motor, the energy absorbed by the driving motor is 1333 watts.
\end{abstract}

Keywords: alternative energy, free energi, flywheel generator, power

\begin{abstract}
ABSTRAK: Peningkatan kebutuhan energi listrik dipengaruhi oleh pertambahan jumlah penduduk. Peningkatan tersebut tidak diimbangi dengan ketersediaan energi listrik terutama di beberapa daerah terpencil yang ada di Kalimantan Utara. Pembangkit listrik yang berbasis free energi menjadi solusi alternatif dalam mencukupi ketersediaan energi listrik. Free energi merupakan metode pemanfaatan energi tanpa menggunakan bahan bakar. Salah satu free energi yang dikembangkan adalah flywheel generator. Tujuan penelitian ini adalah merancang sistem pembangkit listrik dengan pemanfaatan flywheel sebagai penyimpan energi serta menghitung dan menganalisis daya flywheel. Hasil penelitian ini menunjukkan bahwa telah dilakukan perancangan pembangkit listrik dengan pemanfaatan flywheel sebagai penyimpan energi dengan daya flywheel sebesar 1.185 watt, dimana dengan penggunaan flywheel pada pembangkit listrik yang menggunakan bantuan motor, maka energi yang diserap motor penggerak tersebut sebesar 1333 watt.
\end{abstract}

Kata kunci: energy alternatif, free energi, flywheel generator, daya

\section{PENDAHULUAN}

Ketersediaan energi listrik nasional pada tahun 2018 mencapai sekitar 64.925 MW. Dari tahun ke tahun konsumsi listrik di Indonesia mengalami peningkatan. Berdasarkan data dari Perusahaan Listrik Negara (PLN), total pemakaian listrik di Indonesia sebesar $271 \mathrm{TWh}$ mengalami peningkatan rata-rata sekitar $4,8 \%$ per tahun selama 5 tahun terakhir. Peningkatan ini sesuai dengan kenaikan jumlah pelanggan energi listrik di Indonesia. Di Provinsi Kalimantan Utara ketersediaan energi listrik adalah sekitar $204 \mathrm{MW}$ dengan konsumsi energi listrik mencapai $556 \mathrm{GWh}$. Rasio elektrifikasi di Provinsi Kalimantan Utara ditargetkan meningkat dari sekitar 99,26\% pada tahun 2019 menjadi sekitar 100\% pada tahun 2020. Kebutuhan energi listrik di Provinsi Kalimantan Utara diproyeksikan akan mengalami pertumbuhan rata-rata sekitar $42,2 \%$ per tahun dalam periode 10 tahun ke depan, atau sekitar 18,3\% per tahun untuk periode 20 tahun ke depan [1] .

Berdasarkan pemaparan kebutuhan energi tersebut, maka perlu adanya sumber energi alternatif yang mampu menyediakan kebutuhan energi listrik yang tidak tergantung pada sumber energi minyak bumi dan batubara. Terntu saja energi alternatif yang dimaksud adalah energi yang mampu menghasilkan daya yang cukup untuk kebutuhan industri skala kecil maupun sekala menengah, dengan daya yang mencapai 1000 Watt. Salah satu energi alternatif yang mampu menunjang 
kebutuhan tersebvut adalah pembangkit listrik alternatif dengan pemanfaatan flywheel sebagai penyimpanan energi.

Roda gila (Flywheel) merupakan suatu komponen dari mesin yang mampu menyimpan energi kinetik dari gerak putar (rotasi) poros engkol dan untuk menstabilkan putaran mesin. Roda gila (Flywheel) terhubung pada ujung poros engkol mesin yang menerima daya putar dari piston selama langkah kerja flywheel berfungsi sebagai penyimpanan energi, yang mana menyimpan energi saat daya mesin melebihi kebutuhan dan melepaskannya daya mesin lebih kecil dari kebutuhan. Dapat dimanfaatkan sebagai kontrol dari terjadinya suatu perubahan kecepatan, mampu membuat crankshaft berputar secara terus menerus sehingga mesin beroperasi dengan lembut [2]. Flywheel adalah sebuah komponen yang dapat dipergunakan untuk meredam perubahan kecepatan dengan memanfaatkan kelembaman putaran [3]. Dari kelembaman roda gila dapat menyimpan energi dengan memanfaatkan gerak rotasi pada flywheelsehingga memperoleh energi kinetik rotasi yang dipengaruhi oleh torsi.

Berdasarkan hal tersebut maka tujuan penelitian ini adalah untuk melakukan perancangan pembangkit listrik alternatif dengan pemanfaatan flywheel sebagai penyimpan energy yang mampu menghasilkan daya luaran 1000 watt.

\section{METODOLOGI PENELITIAN}

Dalam penelitian ini menggunakan metode eksperimen, dimana peneliti melakukan perancangan dan analisa terhadap pembangkit listrik alternatif dengan memanfaatkan flywheel sebagai penyimpan dan penerus energi.

Proses perancangan alat bertujuan untuk mendapatkan desain prototipe sesuai dengan kriteria dari flywheel generator. Secara garis besar skema kerja dari rancang bangun pembangkit listrik alternatif dengan pemanfaatan flywheel sebagai penyimpan energy yang dilakukan perancangan ditunjukkan pada gambar 1 berikut.

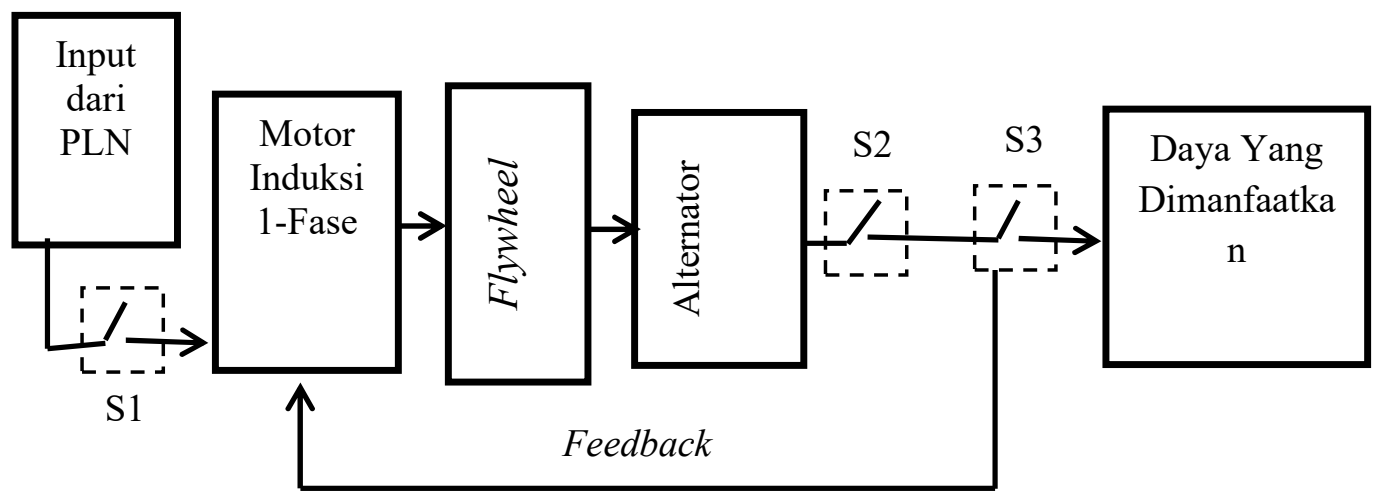

Gambar 1. Skema kerja alat

Berdasarkan skema kerja alat diatas, jika switch 1 dinyalakan maka arus listrik dari PLN akan terhubung ke motor penggerak, sehingga rotor pada motor penggerak berputar. Dari putaran motor penggerak tersebut ditransmisikan ke flywheel dan dari flywheel ditransmisikan ke alternator. Setelah tegangan alternator mencapai 230 volt switch 1 dimatikan, kemudian switch 2 dinyalakan agar motor penggerak mendapatkan suplai listrik dari alternator. Switch 3 dinyalakan untuk memanfaatkan energi listrik yang dihasilkan dari mesin pembangkit listrik tersebut.

1) Perhitungan torsi pada motor

Torsi merupakan momen putar atau besarnya gaya yang dibutuhkan untuk melakukan percepatan rotasi [4]

Untuk sebuah motor listrik dengan daya (P) dan putaran (n), besarnya torsi $(\mathrm{T})$ yang dihasilkan oleh motor listrik tersebut dapat ditentukan dengan persamaan (1) berikut [2]. 
183 Ruslim, Wiwing Herianto, Hadi Santoso. Perancangan Pembangkit Listrik Alternatif Dengan Memanfaatkan Flywheel Sebagai Penyimpan Energi Berdaya 1000 Watt

$\mathrm{P}=\mathrm{T} . \omega$

Dimana $\omega$ merupakan besarnya kecepatan sudut yang diturunkan dari persamaan putaran sebagaimana persamaan (2);

$$
\omega=2 \pi \cdot \frac{n}{60}
$$

2) Perhitungan putaran pada flywheel

Dalam suatu sistem yang memiliki transmisi yang jaraknya cukup jauh sehingga memisahkan antar kedua buah poros yang menyebabkan tidak memungkinkan penggunaan transmisi dengan dengan roda gigi, maka pran $V$-belt sebagai suatu solusi yang dapat dipergunakan. V-belt merupakan sebuah transmisi penghubung kedua poros untuk mentransmisikan putaran dan daya yang terbuat dari karet dan memiliki penampang trapesium. Penggunaan $V$-belt dililitkan mengelilingi ke alur pulley yang berbentuk $\mathrm{V}$ juga. Bagian sabuk yang melilit pada pulley akan terjadi lengkungan sehingga bagian dalam sabuk akan bertambah lebar [4]

Transmisi sabuk-V dalam sistem pembangkit ini ada dua yaitu motor ke flywheel dan flywheel ke alternator dapat dilihat dalam persamaan (3) berikut [4].

$$
i=\frac{n_{1}}{n_{2}}=\frac{d_{1}}{d_{2}}
$$

3) Menghitung torsi yang ditransmisikan ke flywheel

Menghitung torsi yang ditransmisikan untuk memutar pulley yang terhubung dengan flywheel yaitu menggunakan perbandingan sesuai persamaan (4):

$$
\frac{\mathrm{T}_{2}}{\mathrm{~T}_{1}}=\frac{n_{1}}{n_{2}}
$$

\section{4) Menghitung torsi flywheel}

Torsi atau momen gaya merupakan gaya yang menyebabkan benda bergerak melingkar (berputar) di suatu sumbu putar. Torsi dapat didefinisikan ukuran keefektifan gaya tersebut dalam menghasilkan putaran atau rotasi mengelilingi sumbu putar tersebut, sehingga torsi sangat berpengaruh terhadap besarnya daya yang dihasilkan suatu benda yang berputar [2].

Besar torsi (T) yang dihasilkan oleh flywheel yaitu dengan perkalian momen inersia (I) dengan percepatan sudut ( $\alpha$ )didapatkan dengan persamaan (6) berikut [2].

$$
\mathrm{T}=\mathrm{I}
$$

Dimana I adalah momen inersia. Momen Inersia merupakan suatu ukuran tahanan/ kelembaman suatu benda terhadap perubahan dalam gerak putar. Berbeda halnya dengan massa benda yang hanya tergantung pada jumlah zat yang terdapat di dalam benda, dan tergantung bagaimana zat-zat atau massa falam benda dapat di destribusi [5]

Momen Inersia yang dilambangkan (I) dengan satuan dalam SI adalah $\left(\mathrm{kg} . \mathrm{m}^{2}\right)$ untuk mendapatkan nilai momen inersia dari suatu benda yang bergerak melingkar adalah dengan mengalikan setengah massa dari flywheel (m) dengan jarak sumbu puar yang dikuadratkan partikel terhadap sumbu putar $\left(\mathrm{r}^{2}\right)$. Secara matematis momen inersia dapat ditulis sebagai berikut [5]: 


$$
\mathrm{I}=\frac{1}{2} \mathrm{M} \cdot r^{2}
$$

Dimana $\alpha$ merupakan besarnya percepatan sudut yang diturunkan dari persamaan kecepatan sudut sebagaimana persamaan (7):

$$
\alpha=\frac{\Delta \omega}{\Delta t}
$$

5) Perhitungan daya flywheel

Daya dalam flywheel merupakan energi yang telah didestribusikan dalam penggerak, sehingga menghasilkan gerak putar pada flywheel [2], karena pada flywheel terjadi gerak rotasi sehingga Flywheel dengan besar torsi (T) dengan kecepatan sudut ( $\omega$ ) maka daya flywheel dapat dihitung sesuai persamaan (8) Berikut:

$$
\mathrm{P}=\mathrm{T} . \omega
$$

6) Daya Output pada alternator

Daya yang dapat dikeluarkan oleh alternator dapat dihitung dengan penurunan persamaan efisiensi sesuai persamaan (9).

$$
\eta=\frac{\text { Daya Output }}{\text { Daya Output }}
$$

\section{HASIL DAN PEMBAHASAN}

\subsection{PEHITUNGAN}

\subsubsection{Perhitungan Torsi Pada Motor}

Untuk menentukan nili dari torsi yang dihasilkan oleh motor penggerak maka terlebih dahulu ditentukan besaran kecepatan sudut yang dihasilkan oleh motor penggerak. Besaran kecepatan sudut yang dihasilkan dari putaran motor penggerak yang tertera pada name plate adalah sebagai mana diturunkan dari persamaan (2). Dengan demikian didapatkan kecepatan sudut sebagai berikut:

$$
\begin{aligned}
& \omega=2 \pi \cdot \frac{n}{60} \\
& \omega=2 \pi \cdot \frac{3011 \mathrm{rpm}}{60} \\
& \omega=315,1 \mathrm{rad} / \mathrm{sec}
\end{aligned}
$$

Berdasarkan persamaan (1) dapat dihitung besarnya torsi yang dihasilkan oleh motor listrik adalah:

$$
\begin{aligned}
\mathrm{T} & =\frac{\mathrm{P}}{\omega} \\
\mathrm{T} & =\frac{1 \mathrm{HP}}{315,1 \mathrm{rad} / \mathrm{sec}} .745 \mathrm{watt} / \mathrm{HP} \\
& =\frac{745 \mathrm{watt}}{315,1 \mathrm{rad} / \mathrm{sec}} \\
\mathrm{T} & =2,36 \mathrm{~N} \cdot \mathrm{m}
\end{aligned}
$$


185 Ruslim, Wiwing Herianto, Hadi Santoso. Perancangan Pembangkit Listrik Alternatif Dengan Memanfaatkan Flywheel Sebagai Penyimpan Energi Berdaya 1000 Watt

\subsubsection{Perhitungan Putaran Pada Flywheel}

Berdasarkan perencanaan untuk pulley yang digunakan yaitu 2:5, besar pulley yang terhubung pada motor penggerak sebesar 2 inch danpada sisi flywheel menggunakan pulley sebesar 5 inch dengan putaran motor penggerak $3.011 \mathrm{rpm}$, Sehingga didapatkan putaran flywheel sebesar:

$$
\begin{aligned}
i= & \frac{n_{1}}{n_{2}}=\frac{d_{2}}{d_{1}} \\
n_{2} & =\frac{n_{1} \cdot d_{1}}{d_{2}} \\
& =\frac{3.011 \mathrm{rpm} \cdot 2 \mathrm{inch}}{5 \mathrm{inch}} \\
n_{2} & =1.204 \mathrm{rpm}
\end{aligned}
$$

Berdasarkan spesifikasi alternator untuk mencapai tegangan 230 volt membutuhkan putaran sebesar $1.500 \mathrm{rpm}$, sedangkan pada flywheel hanya memiliki putaran sebesar $1.204 \mathrm{rpm}$. Besar pulley pada sisi flywheel sebesar 5 inch, maka besar pulley yang dibutuhkan di sisi alternator untuk mencapai putaran $1.500 \mathrm{rpm}$ sesuai dengan persamaan (3) yaitu:

$$
\begin{aligned}
d_{4} & =\frac{n_{3} \cdot d_{3}}{n_{4}} \\
& =\frac{1.200 \mathrm{rpm} .5 \mathrm{inch}}{1500 \mathrm{rpm}} \\
d_{4} & =4 \mathrm{inch}
\end{aligned}
$$

\subsubsection{Menghitung torsi yang transmisi ke flywheel}

Motor penggerak dengan putaran sebesar $3.011 \mathrm{rpm}$ menghasilkan torsi sebesar 2,36 Nm. Sementara itu putaran pada flywheel sebesar 1.204 rpm sehingga besar torsi yang ditransmisikan ke flywheel sesuai [persamaan (4) yaitu sebesar:

$$
\begin{aligned}
\frac{\mathrm{T}_{2}}{\mathrm{~T}_{1}} & =\frac{n_{1}}{n_{2}} \\
\mathrm{~T}_{2} & =\frac{n_{1}}{n_{2}} \cdot \mathrm{T}_{1}(\text { Torsi Input }) \\
& =\frac{3.011 \mathrm{rpm}}{1.200 \mathrm{rpm}} \cdot 2,36 \mathrm{~N} \cdot \mathrm{m} \\
\mathrm{T}_{2} & (\text { Torsi Output })=5,9 \mathrm{~N} \cdot \mathrm{m}
\end{aligned}
$$

\subsubsection{Perhitungan Torsi pada Flywheel}

Flywheel yang digunakan terbuat dari besi cor. Massa flywheel adalah sebesar $30 \mathrm{~kg}$. Diameter luar dari flywheel tersebut sebesar $42 \mathrm{~cm}$. Dari kedua besaran besaran tersebut, maka diperoleh besar momen inersia yang dihasilkan oleh flywheelberdasarkan persamaan (5) adalah sebagai berikut:

$$
\begin{aligned}
\mathrm{I} & =\frac{1}{2} \mathrm{M} \cdot r^{2} \\
& =\frac{1}{2} 30 \cdot\left(42 \mathrm{~cm} \cdot \frac{1 \mathrm{~cm}}{2.100 \mathrm{~m}}\right)^{2}
\end{aligned}
$$




$$
\begin{aligned}
& =\frac{1}{2} 30 \cdot(0,21 \mathrm{~m})^{2} \\
& =15 \mathrm{~kg} \cdot 0,0441 \mathrm{~m}^{2} \\
& =0.66 \mathrm{~kg} \cdot \mathrm{m}^{2}
\end{aligned}
$$

Sementara itu dengan putaran flywheel sebesar $1.204 \mathrm{rpm}$, nilai kecepatan sudutnya dihitung mengikuti persamaan (2). Maka kecepatan sudut yang terjadi pada flywheel adalah sebagai berikut;

$$
\begin{aligned}
\omega & =2 \cdot \pi \cdot \frac{n}{60} \\
& =\frac{2.3,14.1 .204 \mathrm{rm}}{60 \mathrm{~s}} \\
& =\frac{7.561 \mathrm{rpm}}{60 \mathrm{~s}} \\
& =126 \mathrm{rad} / \mathrm{sec}
\end{aligned}
$$

Dalam pengukuran waktu yang dibutuhkan motor penggerak untuk memutar flywheel mencapai putaran $1.204 \mathrm{rpm}$ terdapat kesulitan karena adanya slip saat motor penggerak untuk memutar flywheel. Jika diasumsikan slip pada motor penggerak tersebut diabaikan, maka waktu yang dibutuhkan motor penggerak untuk memutar flywheel mencapai putaran $1.204 \mathrm{rpm}$ yaitu selama 21,1 detik dengan arus motor penggerak $4 \mathrm{~A}$, sehingga percepatan sudut flywheel berdasarkan persamaan (7) sebesar:

$$
\begin{aligned}
\alpha & =\frac{\Delta \omega}{\Delta t} \\
& =\frac{126 \mathrm{rad} / \mathrm{sec}}{21,1 \mathrm{~s}} \\
& =5,97 \mathrm{rad} / \mathrm{sec}
\end{aligned}
$$

Berdasarkan hasil perhitungan besar momen inersia pada flywheel yaitu $0,66 \mathrm{~kg} \cdot \mathrm{m}^{2}$ dengan percepatan sudut $5,97 \mathrm{rad} / \mathrm{s}^{2}$. Sehingga torsi pada flywheel berdasarkan persamaan (6) yaitu sebesar:

$$
\begin{aligned}
\mathrm{T} & =\mathrm{I} \cdot \alpha \\
& =0,66 \mathrm{~kg} \cdot \mathrm{m}^{2} \cdot 5,97 \mathrm{rad} / \mathrm{sec} \\
& =3,94 \mathrm{~N} \cdot \mathrm{m}
\end{aligned}
$$

Maka didapatkan torsi pada motor penggerak yang ditransmisikan ke flywheel yaitu sebesar 5.9 $N . m$ sedangkan torsi pada flywheel yaitu sebesar $3.94 \mathrm{~N} . \mathrm{m}$. Sehingga motor penggerak mampu untuk memutar flywheel.

\subsubsection{Daya pada flywheel} berikut.

Sehingga daya yang dihasilkan oleh flywheel dapat dihitung sebagaimana pada persamaan (8) 
187 Ruslim, Wiwing Herianto, Hadi Santoso. Perancangan Pembangkit Listrik Alternatif Dengan Memanfaatkan Flywheel Sebagai Penyimpan Energi Berdaya 1000 Watt

$$
\begin{aligned}
\mathrm{P} & =\mathrm{T} . \omega \\
& =3,49 \mathrm{~N} . \mathrm{m} .126 \mathrm{rad} / \mathrm{sec}^{1} \\
& =439 \mathrm{watt}+\text { daya motor } 745 \\
& =1.185 \mathrm{watt}
\end{aligned}
$$

\subsubsection{Daya yang mampu dihasilkan alternator}

Daya yang dapat dikeluarkan oleh alternator dapat dihitung dengan penurunan persamaan efisiensi sesuai persamaan 9. Data yang diperoleh berdasarkan spesifikasi yang terdapat pada name plate efisiensi alternator sebesar 100\%, sehingga didapatkan daya keluaran alternator sebesar:

$$
\begin{aligned}
& \eta=\frac{\text { Daya Output }}{\text { Daya Output }} \\
& \mathrm{P}_{\text {Outut }}=\frac{\mathrm{P}_{\text {Input }}}{\eta} \\
& \mathrm{P}_{\text {Outut }}=\frac{1.185 \text { watt }}{1} \\
& \mathrm{P}_{\text {Outut }}=1.185 \mathrm{watt}
\end{aligned}
$$

Dari hasil perancangan dilanjutkan proses manufaktur dari sistem rancang bangun pembangkit lisrik. Bentuk dari peralatan rancang bangun pembangkit listrik alternatif dengan pemanfaatan flywheel sebagai penyimpan energi adalah sebagai mana yang terlihat pada gambar berikut.

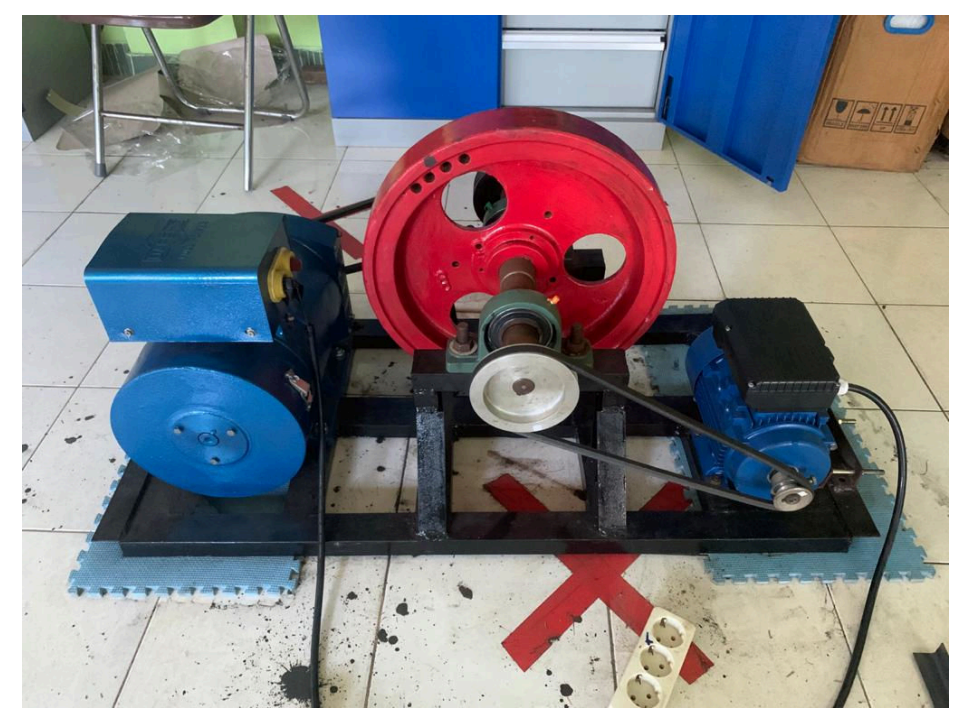

Gambar 2. Tampilan real dari flywheel generator

Setelah semua perangkat mesin sudah terpasang dengan baik, maka dilanjutkan ke pengujian dan pengambilan data. Variabel data yang diambil atau diukur meliputi putaran motor, putaran flywheel, putaran alternator, arus motor, dan tegangan pada alternator. Adapun variabel data pengukuran dimaksud adalah sebagai berikut. 
Tabel 1. pengaruh beban terhadap putaran dan tegangan pada alternator tanpa penambahan flywheel

\begin{tabular}{|c|c|c|c|}
\hline No & $\begin{array}{c}\text { Beban } \\
\text { P (watt) }\end{array}$ & $\begin{array}{c}\text { Putaran Alternator } \\
\boldsymbol{n}(\boldsymbol{r p m})\end{array}$ & $\begin{array}{c}\text { VoltOutput } \\
\text { V (volt) }\end{array}$ \\
\hline $\mathbf{1}$ & 0 & 1523 & 270 \\
\hline $\mathbf{2}$ & 60 & 1488 & 260 \\
\hline $\mathbf{3}$ & 160 & 1444 & 250 \\
\hline $\mathbf{4}$ & 755 & 1200 & 190 \\
\hline
\end{tabular}

Dari data pengujian tabel 4.1 tanpa penggunaan flywheel daya yang dihasilkan oleh alternator pada beban 755 watt yaitu sebesar 190 watt tidak memenuhi kebutuhan untuk mensuplai ke motor penggerak yaitu sebesar 220 volt berdasarkan dari name plate yang terdapat pada motor.

Tabel 2. Pengaruh beban terhadap putaran dan tegangan pada alternator penambahan flywheel

\begin{tabular}{|c|c|c|c|}
\hline No & $\begin{array}{c}\text { Beban } \\
\text { P (watt) }\end{array}$ & $\begin{array}{c}\text { Putaran Alternator } \\
\boldsymbol{n}(\boldsymbol{r p m})\end{array}$ & $\begin{array}{c}\text { VoltOutput } \\
\text { V (volt) }\end{array}$ \\
\hline $\mathbf{1}$ & 0 & 1504 & 270 \\
\hline $\mathbf{2}$ & 60 & 1494 & 260 \\
\hline $\mathbf{3}$ & 160 & 1458 & 260 \\
\hline $\mathbf{4}$ & 755 & 1395 & 240 \\
\hline
\end{tabular}

Dari data pengujian tabel 4.2 dengan penggunaan flywheel daya yang dihasilkan oleh alternator pada beban 755 watt yaitu sebesar 240 volt sehingga cukup untuk memenuhi kebutuhan untuk mensuplai ke motor penggerak.

Adapun pengaruh dengan penambahan flywheel dan tanpa penambahan flywheel terhadap putaran alternator, jika diberi beban yang sama pada alternator. 
189 Ruslim, Wiwing Herianto, Hadi Santoso. Perancangan Pembangkit Listrik Alternatif Dengan Memanfaatkan Flywheel Sebagai Penyimpan Energi Berdaya 1000 Watt

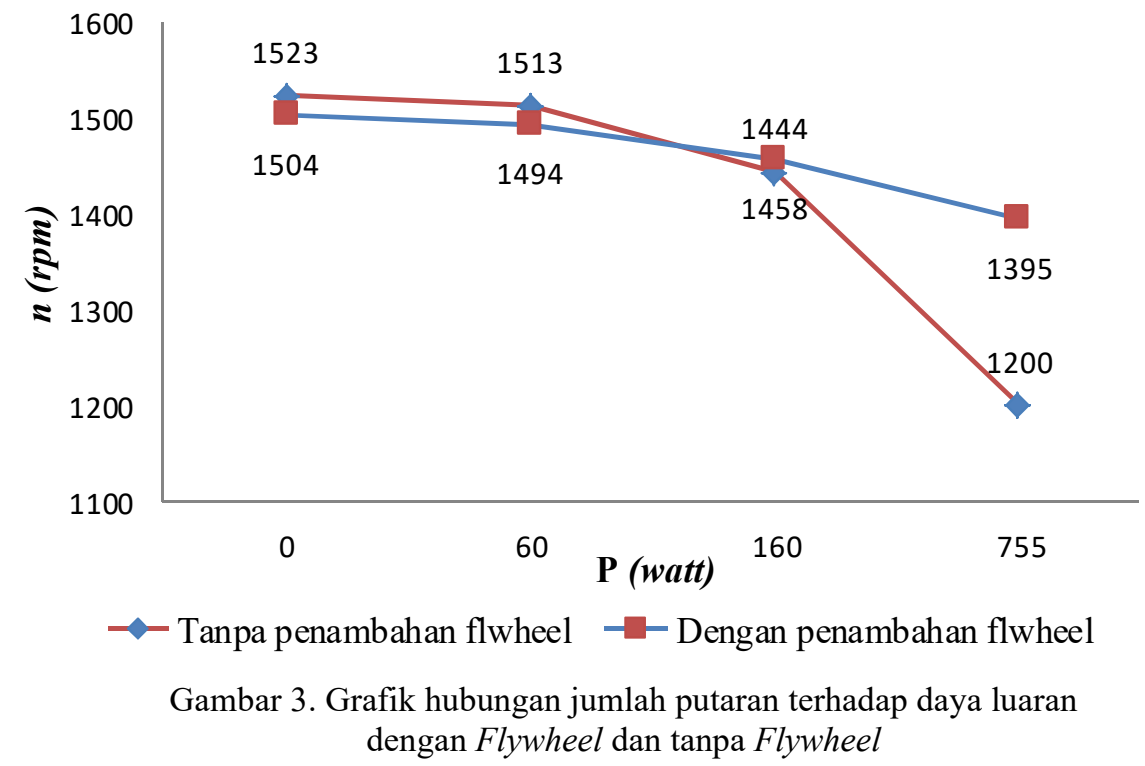

Flywheel dapat menyimpan energi dapat dimanfaatkan untuk menstabilkan putaran pada generator listrik, agar putaran pada generator listrik lebih stabil dan torsi lebih besar. Sehingga pada saat generator listrik mengalami beban yang berlebih, roda gila mampu melipat gandakan energi dan putaran yang cukup untuk alternator. Sehingga generator listrik tidak mengalami penurunan putaran saat terjadi beban [6]. Hal yang sama ditunjukkan pula dalam penelitian ini yaitu, putaran alternator tanpa penggunaan flywheel ketika diberi beban mengalami penurunan secara drastis, namun dengan penggunaan flywheel putaran alternator lebih stabil dan pada saat pemberian beban alternator tidak mengalami penurunan putaran yang berlebihan, dikarenakan adanya energi yang tersimpan pada flywheel untuk menstabilkan putaran.

Adapun pengaruh beban daya pada alternator terhadap konsumsi daya pada motor penggerak dengan pembebanan 60 watt, 160 watt, 755 watt tanpa penambahan flywheel dapat dilihat berdasarkan grafik berikut.

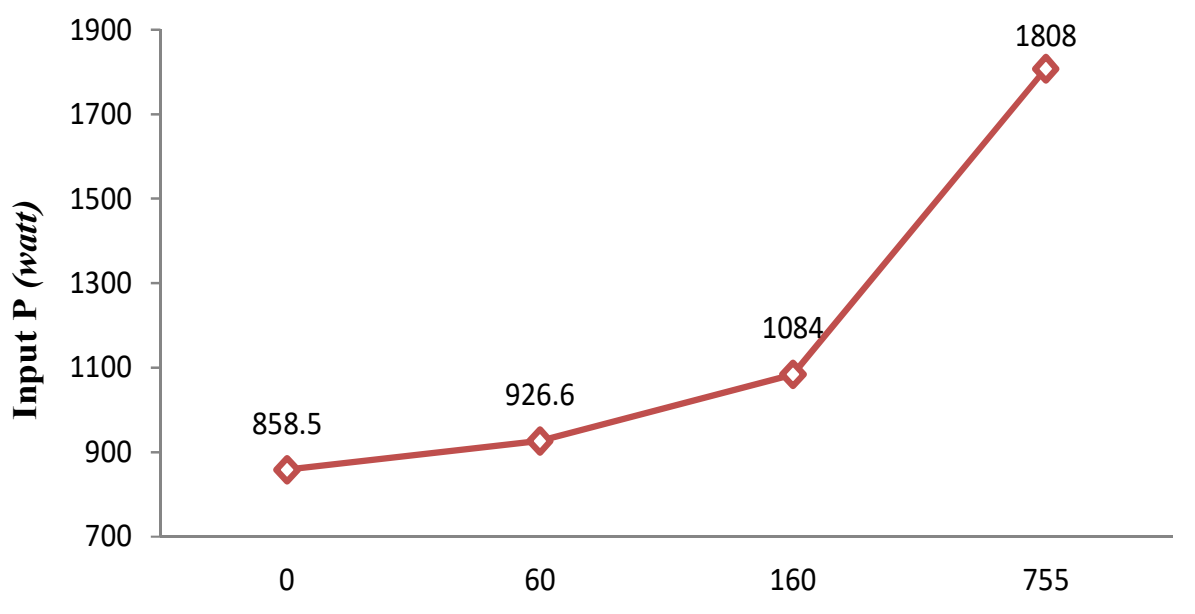

Gambar 4. Grafik hubungan daya masukan dan daya luaran motor tanpa Flywheel 
Berdasarkan grafik pada gambar 4 diatas jika motor penggerak tanpa beban, daya serap motor penggerak sebesar 859 watt. Ketika diberi beban sebesar 60 watt pada alternator daya serap motor penggerak mengalami sedikit kenaikan sebesar 68 watt dari 859 watt menjadi 927 watt. Pada beban 160 watt pada alternator daya serap motor mengalami kenaikan sebesar 158 watt dari 927 watt menjadi 1085 watt, dan pada beban 755 watt pada alternator daya serap motor penggerak mengalami kenaikan sangat sebesar yaitu 723 watt dari 1085 watt menjadi 1808 watt. Namun daya serap dari motor penggerak jauh lebih besar dari daya yang dihasilkan oleh alternator.

Adapun pengaruh beban daya listrik pada alternator terhadap konsumsi daya pada motor penggerak dengan pembebanan 60 watt, 160 watt, 755 watt dengan penambahan flywheel dapat dilihat berdasarkan grafik berikut.

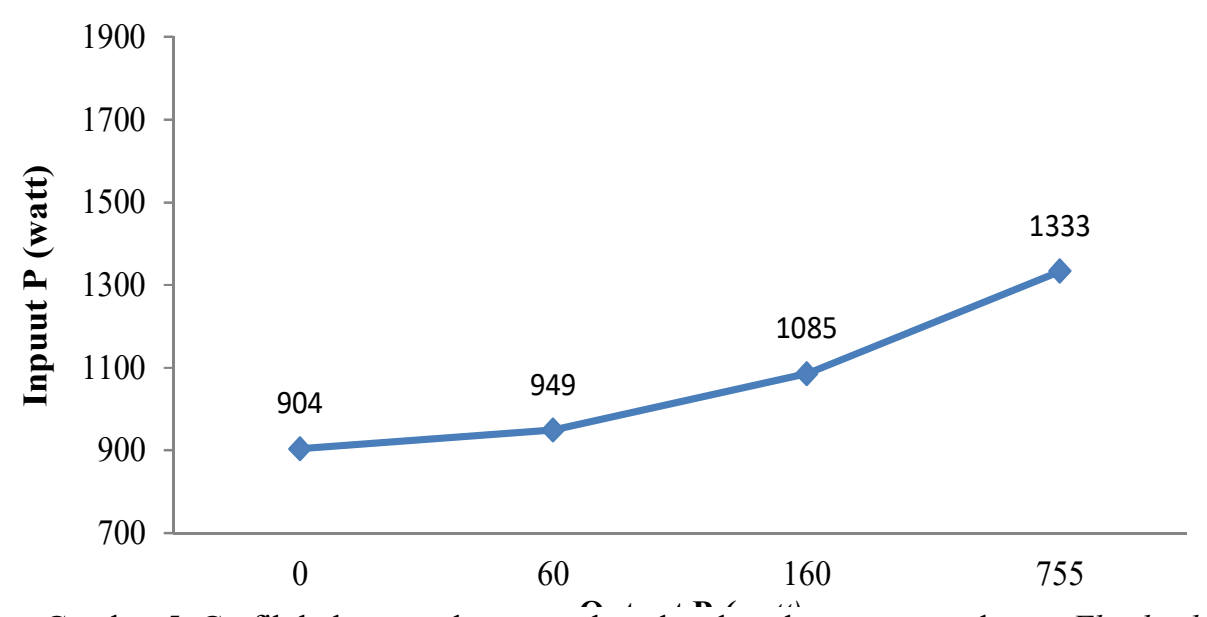

Gambar 5. Grafik hubungan daya masukan dan daya luaran motor denganFlywheel

Penggunaan flywheel dalam suatu sistem pembangkit listrik dapat menjadi solusi dapat meningkatkan kinerja dari sebuah pembangkit dalam mengatasi flutuasi beban [7]. Dalam peneliian ini menunjukkan bahwa jika motor penggerak tanpa beban, daya serap motor penggerak sebesar 904 watt. Ketika diberi beban sebesar 60 watt pada alternator daya serap motor penggerak mengalami sedikit kenaikan yaitu sebesar 45 watt dari 904 watt menjadi 949 watt. Pada beban 160 watt pada alternator daya serap motor penggerak mengalami kenaikan sebesar 136 watt dari 949 watt menjadi 1085 watt, dan beban 755 watt pada alternator daya serap motor penggerak mengalami kenaikan sebesar 245 watt dari 1085 watt menjadi 1333 watt., Namun daya serap dari motor penggerak lebih besar dari daya yang dihasilkan oleh alternator.

Adapun pengaruh penambahan flywheel dan tanpa penambahan flywheel terhadap konsumsi daya pada motor penggerak, jika diberi beban yang sama yaitu sebesar 60 watt, 160 watt, dan 755 watt dapat dilihat berdasarkan grafik berikut ini. 
191 Ruslim, Wiwing Herianto, Hadi Santoso. Perancangan Pembangkit Listrik Alternatif Dengan Memanfaatkan Flywheel Sebagai Penyimpan Energi Berdaya 1000 Watt

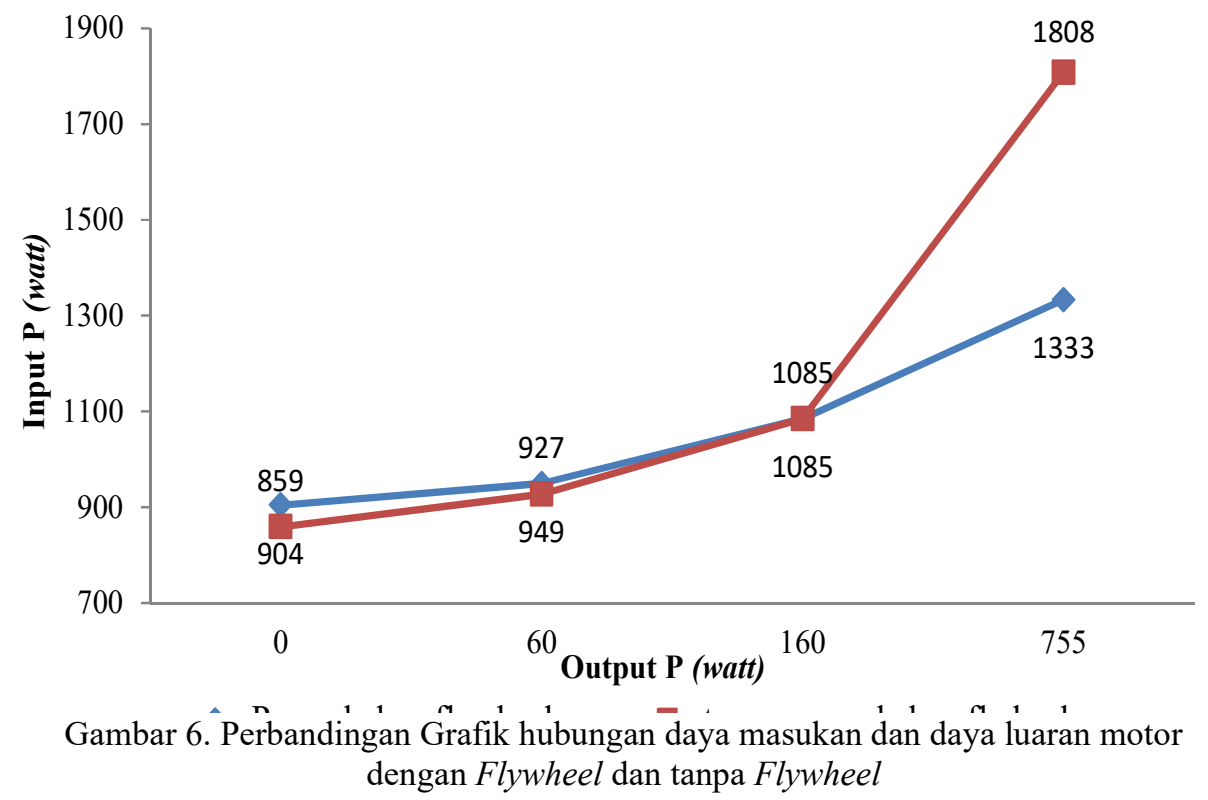

Perancangan pembangkit listrik dengan mengaplikasikan flywheel kedalam generator listrik, agar dapat meningkatkan daya pada alternator dan menstabilkan tegangan yang dihasilkan oleh alternator [5]. Dan penelitian dengan menggunakan simulator turbin angin savonius prototype menunjukkan bahswa flywheel yang digunakan memiliki momen inersia sebesar $0.00121 \mathrm{~kg} . \mathrm{m}^{2}$. dalam penggunaan flywheel menghasilkan kelebihan energi dengan persentase peningkatan rata-rata yaitu sebesar $58,0475 \%$ dan efesiensi dengan penggunaan flywheel disetiap penambahan beban tertinggi yaitu sebesar 0,004010 \%.[3]. Dalam peneneliaian ini mengukur daya serap motor penggerak ketika diberi pembebanan menunjukkan bahwa dalam penggunaan flywheel dapat menghemat penggunaan sumber daya listrik untuk suplay ke motor penggerak, dimana tampa penggunaan flywheel daya serap motor penggerak 1808 watt, sedangkan dalam penggunaan flywheel daya serap motor hanya dibutuhkan 1.333 watt dengan beban alternator yang sama, dikarenakan dalam penggunaan flywheel motor penggerak mendapatkan bantuan energi dari sehingga motor tidak perlu mengeluarkan yang tenaga besar.

\section{KESIMPULAN} bahwa;

Berdasarkan hasil perhitungan dan analisa sebagai mana diuraikan maka dapat disimpulkan

1) Telah dilakukan perancangan pembangkit listrik alternatif dengan pemanfaatan flywheel sebagai penyimpan energy yang diaplikasikan ke dalam sistem pembangkit listrik dengan meningkatkan daya putar pada motor pengarak yang ditransmisikan ke generator.

2) Daya yang dihasilkan oleh flywheel dalam perancangan ini yaitu sebesar 1,185 watt.

3) Berdasarkan data hasil pengujian didapatkan bahwa dengan penggunaan flywheel putaran alternator ketika diberi beban lebih stabil dan daya serap motor penggerak dengan penggunaan flywheel lebih kecil dimana beban alternator sebesar 755 watt, energi yang diserap motor penggerak tanpa penggunaan flywheel adalah sebesar 1808 watt. Sedangkan dengan penggunaan flywheel energi yang diserap motor penggerak adalah sebesar 1,333 watt. 


\section{DAFTAR PUSTAKA}

[1] Tim Rancang Umum Kelistrikan Nasional, Kementrian Energi Dan Sumber Daya Mineral Jakarta, 2019.

[2] M. Cummins, A. P. Rachmawan, I. M. Ariana, and I. Gerianto, "Analisa Pengaruh Flywheel dan Firing Order Terhadap Proses Kerja Mesin Diesel." Jurnal Teknik Sistem Perkapalan, vol. 1, no. 1, pp. 1-6, 2014

[3] J. Julpardi, "ANALISIS EFEKTIFITAS PEMANFAATAN FLYWHEEL SEBAGAI BATERAI MEKANIS PADA TURBIN ANGIN SAVONIUS," JTRAIN J. Teknol. Rekayasa Tek. Mesin, vol. 1 , no. 1 .

[4] Sularso, "Dasar perancangan dan elemen mesin, Pradnya Paramita," cetakan 11 Jakarta, 2004

[5] R. Razali and S. Stephan, "Rancang Bangun Mesin Pembangkit Listrik tanpa Bbm Berkapasitas 3000 Watt dengan Memanfaatkan Putaran Flywheel," J. Media Elektro, pp. 45-48, 2017.

[6] M. A. Rokhim and I. Alfi, "RANCANG BANGUN GENERATOR LISTRIK OVERUNITY DENGAN MEMANFAATKAN ENERGI YANG TERSIMPAN PADA FLYWHEEL (RODA GILA)." University of Technology Yogyakarta, 2019.

[7] S. Marinus, "Studi Aplikatif Roda Gila (Flywheel) Pada Pembangkit Listrik Tenaga Mikrohidro (PLTMH)," J. Tek. Elektro Univ. Tanjungpura, vol. 1, no. 1. 